Old Dominion University

ODU Digital Commons

4-2021

\title{
Influence of Learner Motivational Dispositions on MOOC Completion
}

\author{
Robert L. Moore \\ Old Dominion University, robmoorephd@gmail.com \\ Chuang Wang
}

Follow this and additional works at: https://digitalcommons.odu.edu/stemps_fac_pubs

Part of the Online and Distance Education Commons, and the Science and Mathematics Education Commons

\section{Original Publication Citation}

Moore, R. L., \& Wang, C. (2021). Influence of learner motivational dispositions on MOOC completion. Journal of Computing in Higher Education 33, 121-124. https://doi.org/10.1007/s12528-020-09258-8

This Article is brought to you for free and open access by the STEM Education \& Professional Studies at ODU Digital Commons. It has been accepted for inclusion in STEMPS Faculty Publications by an authorized administrator of ODU Digital Commons. For more information, please contact digitalcommons@odu.edu. 


\title{
1 Influence of learner motivational dispositions on MOOC \\ 2 completion
}

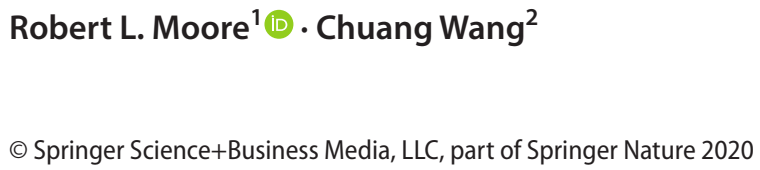

\begin{abstract}
This study examined the role motivational dispositions had on completing a massive open online course (MOOC) using identifiable data from 10,726 students who enrolled in an iteration of the HarvardX MOOC, Super Earths and Life. As part of the course registration process, learners had the option to complete a pre-course survey and self-report information including their level of education, gender and registration motivations. Using these pre-course survey responses, latent profiles AQ1 linked to learners' course performance were created. Results showed education background, gender, and motivation were all significantly related to students' performance. Furthermore, students with intrinsic motivational dispositions performed better than students with extrinsic dispositions, and females performed better than males.
\end{abstract}

Keywords MOOC $\cdot$ Learner dispositions $\cdot$ Motivation $\cdot$ MOOC completion

\section{Introduction}

Massive open online courses (MOOCs) attract tens of thousands of learners from across the world who all have different goals and intentions. While courses attract many enrollees, the completion rates are low (Daniel 2012; Jordan 2015; Maya-Jariego et al. 2020). Several factors impact the non-completion rates, including the free or low cost (Holford et al. 2014) or lack of course relevance for the learner (Howarth et al. 2016). In other words, the openness of the course makes little financial or social penalties for not completing and may hamper motivation to persist in the course. There has been scholarship focusing on issues with course design and development with MOOCs, but

Robert L. Moore

robmoorephd@gmail.com

1 Department of STEM Education and Professional Studies, Darden College of Education and Professional Studies, Old Dominion University, 4301 Hampton Blvd, Suite 4128, Norfolk, VA 23529, USA

2 Faculty of Education, University of Macau, Taipa, Macau, China 
there needs to also be scholarship on the learner's intended purpose for enrolling in a MOOC (Brooker et al. 2018; Maya-Jariego et al. 2020).

For MOOCs, there are a wide variety of learner interests that will bring them to the course-including curiosity about the subject (Christensen et al. 2013; Daniel 2012), an interest in social interaction and networking potential (Zheng et al. 2015), interest in non-formal learning opportunities (Milligan and Littlejohn 2017) or professional development (Brooker et al. 2018). As scholarship with MOOCs continues to evolve, it is necessary to examine the learner motivations and interests in enrolling in a MOOC and ultimately how that influences their persistence in the course.

While motivation has been linked both to MOOC student engagement and performance (Chen and Jang 2010; de Barba et al. 2016; Howarth et al. 2016; Sujatha and Kavitha 2018; Zheng et al. 2015), it is important to identify the type of motivation associated with high engagement and performance within the MOOC learning environment. Motivation is particularly relevant for the MOOC environment because learners must self-regulate their learning to move themselves through the course content (Kizilcec et al. 2017). Motivation can be intrinsic or extrinsic (Ryan and Deci 2000) and these two types of motivation can be linked to the establishment and pursuit of learning goals (Schumacher and Ifenthaler 2018). A desire to explore a topic because of an interest in improving one's knowledge in that topic would be an example of intrinsic motivation; an extrinsic motivation would be pursuing a topic for professional development or career advancement (Brooker et al. 2018; Pintrich 1999). Since MOOCs attract diverse learners, there is the potential that a single MOOC could attract learners with different motivational dispositions where some participants may have enrolled because of interest in learning about a specific topic (intrinsic) and others may be enrolling in pursuit of a certificate (extrinsic) (MayaJariego et al. 2020).

Researchers have examined the relationship between student goals and their MOOC completion. Wilkowski et al. (2014) found that nearly half of the variance in MOOC participation could be predicted by students' goals shared at the start of the course. In their study of MOOC participation and completion, Konstan et al. (2015) discovered that most of the reasons that learners enrolled had little to no effect on course completion. Instead, the learners' self-reported intention of completing the MOOC was a significant predictor of course completion. To further examine this relationship, this current study uses identifiable data in a novel way that allows for a link between what the students' shared in their pre-course survey and how they performed in the course. Additionally, this study has included the level of education and gender of participants to examine what relationship, if any, these demographic factors have on either the motivational dispositions or the course completion.

\section{Conceptual framework}

\section{Self-determination theory}

Motivation is an interesting concept. It is a significant factor in dictating a person's behavior, but it is not always clear and evident from external observation 
(Schumacher and Ifenthaler 2018). This is even more important in the consideration of learners in open online learning environments such as MOOCs as there is limited direct interaction or observation between the instructor and the learner. In these online environments, the learner's decisions on how to, or not to, engage with the content and their classmates can be significantly influenced by motivation (Barak et al. 2016; Deimann and Bastiaens 2010).

Self-determination theory (SDT) serves as the conceptual framework for this study because of its extensively supported linkages to motivation (Firat et al. 2018). Chen and Jang (2010) propound that motivation in online environments is best articulated through SDT. Hsu et al. (2019) identified the SDT factors of autonomy, competence, and relatedness as having influence on motivation. When these needs are met for the learner, they can accomplish positive learning outcomes and can result in improved learner engagement within MOOCs (Lan and Hew 2020) In their examination of learning engagement in a MOOC, Lan and Hew (2020) found a significant correlation between engagement and SDT factors of autonomy, relatedness and competence. The structure of a course that gives learners that ability to make choices about how and when they engage with the material fosters their sense of autonomy (Hsu et al. 2019). This autonomy is found in MOOCs where students are able to have control over the courses they enroll in and how they choose to move through the course (Lan and Hew 2020). The sense of competence comes from the learner's perceptions that they have learned or mastered the content (Hsu et al. 2019). These are demonstrated in MOOCs in a couple of ways, including showing progress bars or dashboards and through assessments that give immediate feedback. The ability to track progress allows for learners to self-regulate their learning and make the necessary adjustments to reach their ultimate learning goals (Kizilcec et al. 2017; Pintrich 1999). And finally, relatedness deals with the connection between the learner and the applicability of the content. When an instructor is able to make clear how the content is applicable to the leaner, they have a higher sense of relatedness (Hsu et al. 2019). Fostering this sense of relatedness is particularly important for learners who want to improve their learning or develop workplace skills, as they will be more receptive to content with a real-world context (Milligan and Littlejohn 2017).

\section{Relationship between learner motivation and MOOC completion}

Completing a MOOC requires a learner to have persistence. In their analysis of student performance goals, Harackiewicz et al. (2002) found that students with strong performance goals (e.g. goals that are recognition-focused) demonstrated higher levels of participation and achievement in comparison to those with weak performance goals. Students who have a clear goal will perform better because they will be able to monitor and adjust their learning to ensure that they are headed towards that goal (Pintrich 1999). One such goal could be workplace application and improvement, a common motivation for students enrolling in a MOOC (Milligan and Littlejohn 2017). While there can be different ways to demonstrate mastery in a MOOC, a typical way is through a course completion certificate. In addition to the performance 
goals, professional development has also been found to be a factor in motivation of MOOC learners (Brooker et al. 2018; Milligan and Littlejohn 2017).

Hsu et al. (2019) argued that the high attrition rates and equally high demand for online courses necessitates that SDT is examined to better understand its application to online learning environments. The interest in addressing attrition rates for MOOCs remains. Thus using SDT to conceptualize learner behaviors is useful, and motivation has been found to be a factor in students' learning outcomes and course completion (Brooker et al. 2018; Gunawardena et al. 2010; Lim 2004; Sujatha and Kavitha 2018).

\section{The current study}

The low completion rate of MOOCs is frequently discussed, as the average is estimated to only be about $13 \%$ (Jordan 2015). While this number may seem low, it is often calculated by looking at the total enrollment of a course and the number of students who successfully completed it. The flaw in this type of analysis is that it does not take into account that learners have various reasons for enrolling in a MOOC (Wilkowski et al. 2014; Zheng et al. 2015). Because courses are offered at no cost, there is a low barrier of entry, so many students register and then never return to the course (Breslow et al. 2013). Additionally, the various motivations for starting a MOOC can impact learner activity and participation that is not captured through an analysis of completion rates (Breslow et al. 2013; Milligan et al. 2013).

The purpose of this study is to provide a more nuanced examination of MOOC learner behavior, specifically by using their self-reported motivational dispositions and how those influenced their performance in the course. The focus on motivation is relevant as researchers have previously linked this as a predictor of MOOC completion and engagement (Sujatha and Kavitha 2018; Xiong et al. 2015).

The research questions that guided this study were:

1. Are there underlying latent profiles of online students' motivation to learn? If so, what are these profiles?

2. Do the students classified by their latent profiles of motivation differ in their performance in the online course and intention to complete the course?

\section{Method}

This research study used a latent profile analysis (LPA) which is a form of latent class analysis with a person-centered approach. Unlike variable-centered approaches (e.g. analysis of variance and regression) that examine relationships between independent and dependent variables, LPA can account for unobserved heterogeneity in the data and discover certain groups of students among those who completed the courses (McCutcheon 1987). In this study, the underlying latent profiles of online students' motivation to register in the course were identified with LPA. 
Influence of learner motivational dispositions on MOOC...

\section{Data collection and clean-up}

The identifiable data used in this study was shared through a data use agreement with the Harvard University Office of the Vice Provost for Advances in Learning (VPAL). The course used was the 2015 iteration of the HarvardX Super Earths and Life MOOC. As part of the registration process, learners were presented with a pre-course survey that asked them for their demographics, intentions, and motivations for the course. This was a post hoc analysis and there was no communication between researchers and learners or course instructors.

The data collection clean-up process is outlined in Fig. 1. In total, 81,121 learners enrolled in this course. Our first step was to narrow the pool by the gender responses and remove any registrants who either did not answer or provided an invalid response (e.g. 'none' or 'other'). This reduced our participant pool to 76,737 students. We next narrowed by education responses to eliminate students who either did not provide a response or provided an invalid response (e.g. 'none' or 'other'). Our interests for this study were the motivational factors that students had at the start of the course which prompted them to register and would guide their participation in the course. These motivational factors were based on a series of questions using a 4-point Likert scale about the influence of ten different factors (e.g. advance their career, receive a certificate) on their decision to enroll in this MOOC. These questions were developed by Harvard and included as part of the pre-course survey; all the questions were optional. Because we needed to link pre-course responses with course assessment grades, we removed any students who had more than three motivation questions missing. Our final step was to remove any learners who did not have a valid course grade (e.g. did not attempt, did not score any points) and this gave us the 10,726 students for the study.

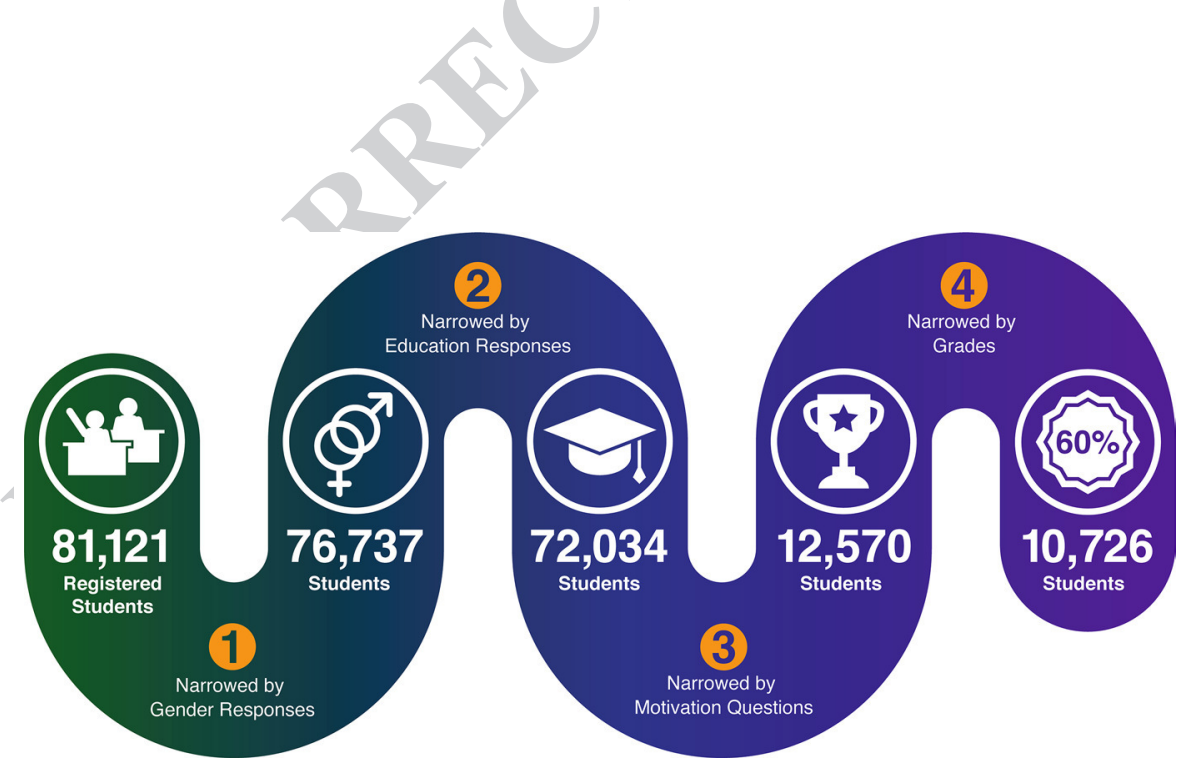

Fig. 1 Data clean up process 


\section{Participants}

A total of 10,726 students who had a valid grade from the course were included in this study. These students included 6156 (57.4\%) males and 4570 (42.6\%) females. Of these students, 4889 (45.6\%) completed elementary through high school, 4142 (38.6\%) had a college degree, $1472(13.7 \%)$ had a masters' degree, and $223(2.1 \%)$ had a doctorate degree. All participants viewed the course, but $5108(47.6 \%)$ explored the course, and 3840 (35.8\%) completed all of the activities within this course.

\section{Context}

Super-Earths and Life is a MOOC offered on the edX platform through the HarvardX program of study. The course is classified by HarvardX as an introductory level course in the Physics subject area. The studied course was the instructorpaced version which was offered on a 6-week schedule with a suggested learner effort of 3-5 h/week. The course ran from 10/13/2015 to 11/29/2015. This course focused on the intersection of astronomy and biology and considers the presence of alien life. The course has as its learning objectives understanding the origin of life on Earth, exploring the discovery of planets, examining the factors that make a planet inhabitable, and discussing how we search the universe for signs of life. Enrollment is open to anyone interested in the content and there are no pre-requisites.

\section{Instrument}

During course registration, learners were asked to rate the importance of their reasons for choosing to register for this course, on a Likert scale from 0 (not important) to 4 (extremely important). The ten items were: (1) engaging in lifelong learning; (2) curiosity about online learning; (3) advancing my career; (4) advancing my formal education; (5) learning from the best professors and universities; (6) better serving my community; (7) accessing learning opportunities not otherwise available; (8) earning a certificate; (9) participating in an online community, and (10) learning about course content. These items were designed by Harvard Uniyersity Office of the Vice Provost for Advances in Learning, and students' responses to these ten items were used for classifying students. The internal consistency for students' responses to these ten items was .80 , which is satisfactory. In addition, students reported their gender, education level, and the number of online courses completed. The dataset also included log files that indicated whether the student viewed, explored, or completed the course. Additionally, the student's final grade, given as a percentage score and a pass/fail indicator, was also included in the dataset. 


\section{Procedure}

The optimal number of latent profiles underlying the data was determined by the results from LPA with Mplus version 7.0 (Muthén and Muthén 2012). Analysis compared $k-1$ and $k$-profile models until the successive model fit no longer showed better fit to the data. Statistical model fit was evaluated using multiple fit indices including the Bayesian information criteria (BIC), adjusted BIC (ABIC), the Lo-Mendell-Rubin likelihood ratio test (LMR-LRT), and the bootstrap likelihood ratio test (BLRT). Smaller values of the BIC and ABIC indicate a better fit. Significant LMR-LRT and BLRT results indicate a better fit. Entropy, a measure of classification uncertainty, was also used to determine the fit of the model. The entropy ranges from 0 to 1 , with higher values indicating good classification of participants.

Analysis of covariance (ANCOVA) was used to compare subgroups (classified by latent profiles) derived from LPA on participants' performance at the online course measured by grade after the control of students' education level, gender, status of current course status, and reasons to register in this course, to see if students differed in their performance in the course with respect to their motivation profiles. Number of previously completed online courses was used as a covariate.

\section{Results}

\section{Motivation profiles}

Table 1 presents the model fit information for the LPA models addressing the first research question. A two-profile solution fitted the dataset and was interpretable. All models under study exhibited high entropy values, indicating a good classification of students. The three-profile model had lower BIC and ABIC values relative to the two-profile model, but the LMR-LRT was non-significant, indicating that the twoprofile model is better. The BLRT, on the other hand, was significant, for both the two-profile and the three-profile solutions. Although the BLRT was more consistent in detecting the correct number of classes within a population (Nylund et al. 2007), the two-profile solution was more interpretable. The BIC, ABIC, BLRT results and substantive consideration all pointed toward the two-profile model.

Table 1 Model fit criteria for one- to three-profile models

\begin{tabular}{lllcll}
\hline Model & BIC & ABIC & Entropy & $\begin{array}{l}\text { L-M-R LRT } \\
(p)\end{array}$ & Bootstrap LRT $(p)$ \\
\hline One-profile & $719,391.12$ & $719,327.57$ & NA & NA & NA \\
Two-profile & $701,983.54$ & $701,885.02$ & .81 & .04 & $<.001$ \\
Three-profile & $697,267.89$ & $697,134.42$ & .79 & .18 & $<.001$ \\
\hline
\end{tabular}

BIC Bayesian information criterion, ABIC adjusted BIC, LRT likelihood ratio test, $L-M-R$ LRT Lo-Mendell-Rubin likelihood ratio test, $N A$ not applicable 
Students classified in Latent Profile 1 endorsed more on items about lifelong learning, curiosity about online learning, learning from the best professors and universities, opportunities not otherwise available, and learning about course content. As a result, these students were labeled as "intrinsic motivation" (Ryan and Deci 2000). On the other hand, students classified in Latent Profile 2 endorsed more on items about advancing my career, advancing my formal education, better serving my community, earning a certificate, and participating in an online community. As a result, these students were labeled as "extrinsic motivation" (Ryan and Deci 2000).

Descriptive statistics about the students' grade with respect to their background information are presented in Table 2.

Results from ANCOVA suggested a statistically significant three-way interaction effect between gender, course completion status, and motivation profiles, $F$ (3, $10,599)=2.76, p=.04$, partial $\eta^{2}<.001$ (small effect size). As a result, data were split into two files: those who completed the course and those who did not complete the course. Follow-up analysis of variance (ANOVA) results showed that for both students who completed the course and those who did not complete the course, education background, gender, and motivation were all significantly related to students' grade achieved at the course. Statistically significant differences were noted for students with various educational backgrounds, $F(3,10,600)=59.43, p<.001$, partial $\eta^{2}=.017$ (small effect size). Students with graduate degrees (masters and doctorate) received significantly higher grades than undergraduate students $(p s<.05)$. Students with intrinsic motivation received significantly higher grades than students with

Table 2 Descriptive statistics of students' grade

\begin{tabular}{|c|c|c|c|}
\hline & $M$ & $S D$ & $N$ \\
\hline \multicolumn{4}{|c|}{ Gender } \\
\hline Male & 43.02 & 36.57 & 6156 \\
\hline Female & 35.44 & 33.81 & 4570 \\
\hline \multicolumn{4}{|l|}{ Education } \\
\hline Elementary-High & 35.92 & 33.90 & 4889 \\
\hline College & 40.07 & 35.74 & 4142 \\
\hline Masters & 49.96 & 38.07 & 1472 \\
\hline Doctorate & 52.84 & 37.61 & 223 \\
\hline \multicolumn{4}{|l|}{ Course completion } \\
\hline Completed & 84.53 & 10.82 & 3840 \\
\hline Not Completed & 14.84 & 13.15 & 6886 \\
\hline \multicolumn{4}{|l|}{ Reasons to register } \\
\hline Undecided & 29.44 & 32.29 & 1006 \\
\hline Browse & 28.06 & 31.25 & 154 \\
\hline Some work & 30.03 & 32.02 & 1695 \\
\hline Certificate & 43.45 & 36.15 & 7866 \\
\hline \multicolumn{4}{|l|}{ Motivation } \\
\hline Intrinsic & 40.92 & 36.27 & 5275 \\
\hline Extrinsic & 38.69 & 34.97 & 5451 \\
\hline
\end{tabular}

Students' grades ranged from 0 to 100 
extrinsic motivation, $F(1,10,602)=7.86, p=.005$, partial $\eta^{2}=.001$ (small effect size) after the control of the number of previous online courses completed online. Similarly, female students received significantly higher scores than male students, $F$ $(1,10,602)=120.28, p<.001$, partial $\eta^{2}=.011$ (small effect size).

Differences were noted between students who did not complete the course and those who completed the course. The main effect for reasons to register was statistically significant for students who did not complete the course. $F(3,6819)=4.67$, $p=.003$, partial $\eta^{2}=.002$ (small effect size). Multiple comparisons showed that students who registered with the intention to receive a certificate performed better than those who were undecided about whether to earn a certificate or to complete all the coursework $(p<.05)$. The difference between those who wanted to pursue a certificate and those who wanted to browse was not statistically significant. Of the students who completed the course, however, students who registered to obtain a certificate performed better than any other groups of students, undecided, browse, and some work $(p s<.001)$.

\section{Discussion}

The present study examined the motivational dispositions of learners enrolled in a MOOC. Researchers have found connections between student performance and engagement and their motivation for enrolling in a MOOC (Lan and Hew 2020; Maya-Jariego et al. 2020; Milligan et al. 2013; Milligan and Littlejohn 2017). MOOC learners will have varied motivations for enrolling in the course and thus varied participation levels (Kizilcec and Schneider 2015). Thus, it is helpful to examine the participation within a course through the learners' motivational dispositions. These dispositions can influence how a learner approaches and engages within the MOOC. Pintrich (1999) suggested that learners focusing on learning and mastery (intrinsic) will be better aligned with self-regulated learning than those focusing on extrinsic goals. In order to understand the dispositions - and be able to classify as either intrinsic or extrinsic-identifiable data is needed to link the self-reported dispositions with the course engagement and completion. This data-both the selfreported information and log files from the course-allowed for the development and analysis of latent profiles for learners. And these profiles provide insight into the relationship between the learners' motivations and performance within the MOOC.

Our first research question asked if there were underlying latent profiles of the MOOC learners' motivations to enroll in the MOOC. To answer this question, we used the responses from learners to a series of motivation questions, and their responses allowed for the creation of two latent profiles connected with either intrinsic or extrinsic motivation (Fig. 2).

This classification aligns well with the research that has suggested that motivation influences engagement and students' final performance in a course (de Barba et al. 2016; Huang and Hew 2016; Maya-Jariego et al. 2020; Milligan and Littlejohn 2017; Sujatha and Kavitha 2018; Xiong et al. 2015). As Fig. 2 shows, the students classified as intrinsically motivated (Latent Profile 1) endorsed more of 


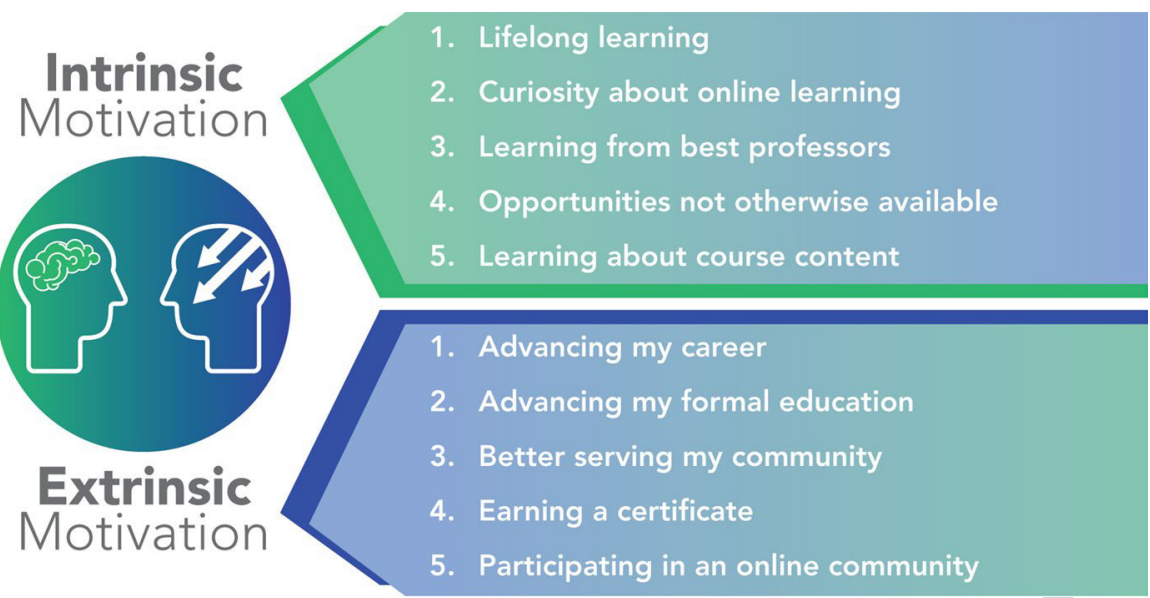

Fig. 2 Latent profiles and associated questions

the items related to internal drivers. This means that the students looked inward to find the motivation to persist within the course.

These students were interested in learning for the sake of learning or to satisfy their own curiosity. For these students, it was more important for them to learn the course content than it was for them to earn an external award, such has a certificate. Firat et al. (2018) posit that learners need to have intrinsic motivation to persist in their program of study. For the students classified as extrinsically motivated (Latent Profile 2), the opposite is true. These students were motivated by some type of external factor-whether it was career or professional development or the awarding of a course completion certificate. A key distinction of an extrinsic orientation is the focus on external factors (e.g. a grade, a teacher) as the indicator of success (Pintrich 1999). Firat et al. (2018) suggest that in an online environment, where instructors have limited direct interaction with learners, the extrinsic motivators can be impactful. The pursuit of a tangible artifact, such as a certificate, can serve as the ongoing motivation that allows a student to persist in a MOOC.

With the latent profiles identified, we next sought to see if learners differed in their performance in the course. The identifiable data allowed us to include not only their motivational dispositions but also their gender, education level and the course performance. The use of their gender and educational level allows for a more robust analysis of the learner behavior. In fact, we found that educational background, gender and latent profile were all significantly related to the grade in the course. In this course, the more highly educated students (those with masters or doctorates) outperformed the undergraduate students. We also found that the female students outperformed the male students. An interesting finding was that when controlling for the number of previous online courses, the students classified in Latent Profile 1 (intrinsic motivation) significantly outperformed the students classified in Latent Profile 2 (extrinsic motivation). The internal motivations highlighted by Firat et al. (2018) 
seem to have allowed for the learners to not only stay engaged but retain more of the information and achieve higher course grades.

As previously noted, some researchers have pointed to the low cost or lack of penalty for non-completion as factors for low MOOC completion rates. In response to the low completion rates, many MOOC providers have turned to certificates as a way to encourage MOOC completion (Bonafini et al. 2017). Our study provides support for their findings. This study found that when students were motivated to receive a certificate, they were more likely to succeed than students without a tangible goal. And while a certificate is considered an extrinsic goal, it can serve as a motivational reference point for learners to keep moving toward (Pintrich 1999). This points back to the role of strong performance goals identified in the study done by Harackiewicz et al. (2002).

\section{Limitations and implications for research}

This study addresses a gap in current research on MOOC completion by considering the learner's motivations. Due to limited access to data, researchers may report on the low completion rates of MOOCs using available data that does not account for the learner's intention for enrolling in the MOOC. This study predicted student course completion based on learner's self-reported motivational dispositions. This novel approach to MOOC research used the creation of latent profiles based on motivational dispositions to explore how motivation influences MOOC completion. These insights provide information that may be helpful both for MOOC learners and course administrators and designers.

The uniqueness of the study is also the source of a limitation. The first limitation is that the sample was determined using self-reported data. Students who either did not complete the pre-course survey or provided invalid responses were removed from the study. This may have resulted in the dropping of students who did pass the course but did not fully complete the pre-course survey. Secondly, we limited our study to those who answered at least seven of the ten motivation questions in the pre-course survey. Again, this did limit the sample size as students who completed some but not all the motivation questions were removed. While this may have resulted in additional students being removed from the study, it was essential that the sample had a majority of the motivation questions so that the latent profiles could be accurately built. And finally, another limitation is that this study only looked at one MOOC. Future research that looked at a self-paced version of this course would be of interest to see if the pacing condition influenced either student motivations or their course performance. Further research across multiple MOOCs offered by different providers and in different subject areas will enhance the empirical data regarding learner motivations and MOOC completion. With the diversity of both courses and learner motivations, it will be useful to continue to explore the relationship between learner motivation and course performance to better identify what is and is not working within the MOOC learning environments. In addition, a closer examination of course performance to consider both completers and non-completers and how that performance might be linked to motivation would be of value. 
Acknowledgements Data used in this study was provided via a data use agreement with the Harvard Vice Provost for Advances for Learning (VPAL) office.

\section{References}

Barak, M., Watted, A., \& Haick, H. (2016). Motivation to learn in massive open online courses: Examining aspects of language and social engagement. Computers \& Education, 94, 49-60. https://doi. org/10.1016/j.compedu.2015.11.010.

Bonafini, F. C., Chae, C., Park, E., \& Jablokow, K. W. (2017). How much does student engagement with videos and forums in a MOOC affect their achievement? Online Learning, 21(4), 223-240. https:// doi.org/10.24059/olj.v21i4.1270.

Breslow, L., Pritchard, D. E., DeBoer, J., Stump, G. S., Ho, A. D., \& Seaton, D. T. (2013). Studying learning in the worldwide classroom research into edX's first MOOC. Research and Practice in Assessment, 8, 13-25.

Brooker, A., Corrin, L., de Barba, P. G., Lodge, J., \& Kennedy, G. (2018). A tale of two MOOCs: How student motivation and participation predict learning outcomes in different MOOCs. Australasian Journal of Educational Technology, 34(1), 73-87. https://doi.org/10.14742/ajet.3237.

Chen, K.-C., \& Jang, S.-J. (2010). Motivation in online learning: Testing a model of self-determination theory. Computers in Human Behavior, 26(4), 741-752. https://doi.org/10.1016/j.chb.2010.01.011.

Christensen, G., Steinmetz, A., Alcorn, B., Bennett, A., Woods, D., \& Emanuel, E. J. (2013). The MOOC phenomenon: Who takes Massive Open Online Courses and why? SSRN Electronic Journal. https:// doi.org/10.2139/ssrn.2350964.

Daniel, J. (2012). Making sense of MOOCs: Musings in a maze of myth, paradox and possibility. Journal of Interactive Media in Education, 3(18), 1-20. https://doi.org/10.5334/2012-18.

de Barba, P. G., Kennedy, G. E., \& Ainley, M. D. (2016). The role of students' motivation and participation in predicting performance in a MOOC. Journal of Computer Assisted learning, 32(3), 218-231. https://doi.org/10.1111/jcal.12130.

Deimann, M., \& Bastiaens, T. (2010). The role of volition in distance education: An exploration of its capacities. The International Review of Research in Open and Distributed Learning, 11(1), 1-16. https://doi.org/10.19173/irrodl.v11i1.778.

Firat, M., Kilinç, H., \& Yüzer, T. V. (2018). Level of intrinsic motivation of distance education students in e-learning environments. Journal of Computer Assisted learning, 34(1), 63-70. https://doi. org/10.1111/jcal.12214.

Gunawardena, C. N., Linder-VanBerschot, J. A., LaPointe, D. K., \& Rao, L. (2010). Predictors of learner satisfaction and transfer of learning in a corporate online education program. American Journal of Distance Education, 24(4), 207-226. https://doi.org/10.1080/08923647.2010.522919.

Harackiewicz, J. M., Barron, K. E., Pintrich, P. R., Elliot, A. J., \& Thrash, T. M. (2002). Revision of achievement goal theory: Necessary and illuminating. Journal of Educational Psychology, 94(3), 638-645. https://doi.org/10.1037/0022-0663.94.3.638.

Holford, J., Jarvis, P., Milana, M., Waller, R., \& Webb, S. (2014). The MOOC phenomenon: Toward lifelong education for all? International Journal of Lifelong Education, 33(5), 569-572. https://doi. org/10.1080/02601370.2014.961245.

Howarth, J. P., D’Alessandro, S., Johnson, L., \& White, L. (2016). Learner motivation for MOOC registration and the role of MOOCs as a university 'taster'. International Journal of Lifelong Education, 35(1), 74-85. https://doi.org/10.1080/02601370.2015.1122667.

Hsu, H.-C. K., Wang, C. V., \& Levesque-Bristol, C. (2019). Reexamining the impact of self-determination theory on learning outcomes in the online learning environment. Education and Information Technologies, 24(3), 2159-2174. https://doi.org/10.1007/s10639-019-09863-w.

Huang, B., \& Hew, K. F. (2016). Measuring learners' motivation level in massive open online courses. International Journal of Information and Education Technology, 6(10), 759-764. https://doi. org/10.7763/IJIET.2016.V6.788.

Jordan, K. (2015). Massive open online course completion rates revisited: Assessment, length and attrition. International Review of Research in Open and Distributed Learning, 16(3), 341-358. https:// doi.org/10.13140/RG.2.1.2119.6963. 
Influence of learner motivational dispositions on MOOC...

Kizilcec, R. F., Pérez-Sanagustín, M., \& Maldonado, J. J. (2017). Self-regulated learning strategies predict learner behavior and goal attainment in massive open online courses. Computers \& Education, 104, 18-33. https://doi.org/10.1016/j.compedu.2016.10.001.

Kizilcec, R. F., \& Schneider, E. (2015). Motivation as a lens to understand online learners: Toward datadriven design with the OLEI Scale. ACM Transactions on Computer-Human Interaction, 22(2), 1-24. https://doi.org/10.1145/2699735.

Konstan, J. A., Walker, J. D., Brooks, C., Brown, K., \& Ekstrand, M. D. (2015). Teaching recommender systems at large scale: Evaluation and lessons learned from a hybrid MOOC. ACM Transactions on Computer-Human Interaction, 22(2), 1-23. https://doi.org/10.1145/2728171.

Lan, M., \& Hew, K. F. (2020). Examining learning engagement in MOOCs: A self-determination theoretical perspective using mixed method. International Journal of Educational Technology in Higher Education, 17(1), 1-24. https://doi.org/10.1186/s41239-020-0179-5.

Lim, C. P. (2004). Engaging learners in online learning environments. TechTrends, 48(4), 16-23. https:// doi.org/10.1007/BF02763440.

Maya-Jariego, I., Holgado, D., González-Tinoco, E., Castaño-Muñoz, J., \& Punie, Y. (2020). Typology of motivation and learning intentions of users in MOOCs: The MOOCKNOWLEDGE study. Educational Technology Research and Development, 68(1), 203-224. https://doi.org/10.1007/s11423-01909682-3.

McCutcheon, A. L. (1987). Latent class analysis. Thousand Oaks, CA: Sage.

Milligan, C., \& Littlejohn, A. (2017). Why study on a MOOC? The motives of students and professionals. The International Review of Research in Open and Distributed Learning, 18(2), 92-102. https:// doi.org/10.19173/irrodl.v18i2.3033.

Milligan, C., Littlejohn, A., \& Margaryan, A. (2013). Patterns of engagement in connectivist MOOCs. MERLOT Journal of Online Learning and Teaching, 9(2), 149-159.

Muthén, L. K., \& Muthén, B. O. (2012). Mplus version 7 [Computer software] (No. 7). Los Angeles, CA: Muthén and Muthén.

Nylund, K. L., Asparouhov, T., \& Muthén, B. O. (2007). Deciding on the number of classes in latent class analysis and growth mixture modeling: A Monte Carlo simulation study. Structural Equation Modeling: A Multidisciplinary Journal, 14(4), 535-569. https://doi.org/10.1080/10705510701575396.

Pintrich, P. R. (1999). The role of motivation in promoting and sustaining self-regulated learning. International Journal of Educational Research, 31(6), 459-470. https://doi.org/10.1016/S0883 -0355(99)00015-4.

Ryan, R. M., \& Deci, E. L. (2000). Intrinsic and extrinsic motivations: Classic definitions and new directions. Contemporary Educational Psychology, 25(1), 54-67. https://doi.org/10.1006/ ceps.1999.1020.

Schumacher, C., \& Ifenthaler, D. (2018). The importance of students' motivational dispositions for designing learning analytics. Journal of Computing in Higher Education, 30(3), 599-619. https:// doi.org/10.1007/s12528-018-9188-y.

Sujatha, R., \& Kavitha, D. (2018). Learner retention in MOOC environment: Analyzing the role of motivation, self-efficacy and perceived effectiveness. International Journal of Education and Development Using Information and Communication Technology, 14(2), 62-74.

Wilkowski, J., Deutsch, A., \& Russell, D. M. (2014). Student skill and goal achievement in the mapping with google MOOC. In Proceedings of the first ACM conference on learning @ scale conference$L @ S^{\prime} 14$ (pp. 3-10). https://doi.org/10.1145/2556325.2566240.

Xiong, Y., Li, H., Kornhaber, M. L., Suen, H. K., Pursel, B. K., \& Goins, D. (2015). Examining the relations among student motivation, engagement, and retention in a MOOC: A structural equation modeling approach. Global Education Review, 2(3), 23-33.

Zheng, S., Rosson, M. B., Shih, P. C., \& Carroll, J. M. (2015). Understanding student motivation, behaviors, and perceptions in MOOCs. In Proceedings of the 18th ACM conference on computer supported cooperative work and social computing-CSCW'15 (pp. 1882-1895). https://doi. org/10.1145/2675133.2675217.

Publisher's Note Springer Nature remains neutral with regard to jurisdictional claims in published maps and institutional affiliations. 
Journal: $\quad \mathbf{1 2 5 2 8}$

Article: $\quad \mathbf{9 2 5 8}$

\section{Author Query Form}

\section{Please ensure you fill out your response to the queries raised below and return this form along with your corrections}

\section{Dear Author}

During the process of typesetting your article, the following queries have arisen. Please check your typeset proof carefully against the queries listed below and mark the necessary changes either directly on the proof/online grid or in the 'Author's response' area provided below

\begin{tabular}{|l|l|l|}
\hline Query & Details Required & $\begin{array}{l}\text { A u th o r's } \\
\text { Response }\end{array}$ \\
\hline AQ1 & $\begin{array}{l}\text { Please check and confirm that the authors and their } \\
\text { respective affiliations have been correctly identified and } \\
\text { amend if necessary. }\end{array}$ & \\
\hline AQ2 & Author: Please provide biography for all authors. & \\
\hline
\end{tabular}

